\title{
WAWASAN PROSES KREATIF PENCIPTAAN KARYA SASTRA
}

\author{
Oleh: Suwardi
}

\section{ABSTRAK}

Proses kreatif penciptaan karya sastra memang membutuhkan 'etos kerja' yang unik dan khas. Dengan 'etos kerja' yang mendasar, pengalaman proses kreatif yang bersifat personal itu dapat dicobakenakan kepada orang lain, sehingga hasil yang diharapkan dapat mencapai 'puncak', yakni memiliki lebih baik (to be and to be better) dari karya yang pernah dihasilkan.

Penciptaan karya sastra memang berproses, tumbuh, dan melalui trial and error., pengarang yang kreatif tidak segera puas dengan karya sekali jadi. namun berusaha mengoreksi dan siap menerima kritik atau bahkan self-kritik, hal ini sangat dipengaruhi oleh pengalaman jiwa masing-masing pengarang.

tahap-tahap proses kreatif penciptaan karya sastra yakni :

1) Tahap penggalian yang meliputi langkah-langkah: (I) kepekaan. (2) sublimitas, (3) abstraksi. (4) menelorkan embrio. dan (5) indkubasi (pengeraman ide). 2) Tahap penuangan yang meliputi : (1) ersatz-stimuli, (2) wishful thinking. (3) rethorika. (4) pathos, (5) utopia, (6) obsesi, (7) chaos, (8) katarsis, dan (9) eksagerasi. 3) Tahap koreksi, dan 4) Tahap intropeksi.

\section{A. PENDAHULUAN}

Manusia pada dasarnya memiliki jiwa kepengarangan. Dalam hal ini Widyamataya (1987 : 5) menjelaskan, manusia itu mempunyai "need for achievement" yaitu dorongan berbuat sesuatu. Ia mempunyai ide-ide, gagasan, inti isi, cita-cita, argumen dan lain-lain yang sarat sebagai modal mengarang. Timbul pertanyaan mudahkah mengarang itu ?

Atmowiloto (1995: 7) dengan nada santai bergumam, mengarang itu gampang karena bisa dipelajari. Pendapat ini bukan tanpa resiko. Artinya, tidak setiap orang yang mempunyai uneg-uneg, segera bisa dituangkan pada kertas. 
Bila ini terjadi, hasil ciptanya menarik untuk dibaca ? Pertanyaan singkat ini akan terjawab jika pencipta karya sastra memperhatikan pertanyaan Nasution (1985 : 17) yakni sedikitnya kita perlu mengerti seluk beluk manusia. Secara psikologi, dan lain-lain. Tentu, pengetahuan ini belum cukup sebagai bekal kepengarangan.

Pekerjaan mengarang, lebih-lebih bagi cipta kreatif, tidak akan semudah yang kita ucapkan. Hal ini telah dikemukakan Wisjnu (1963: 73), pengarang bukan angkatan kertas, bukan angkatan kapstok, dan bukan angkatan dakocan. Hal ini menunjukkan bahwa mengarang bukan sekedar kerja yang mekanik. Maka, Lubis (1981 : .h1535) menegaskan orang hanya mengarang, jika ada sesuatu di dalam jiwanya yang mendesak-desak, memaksanya mengambil pena, potlot, atau mesin ketik, kertas, dan menulis. Bekal ini saja masih harus ditunjang dengan teknik mengarang. Sinyalemen ini menyerukan bahwa proses kreatif perlu etos kerja yang besar dan khusus. Tuntutan ini menghendaki bahwa proses kreatif memang butuh profesionalitas, butuh acuan yang jelas.

Dalam buku "ABC karang mengarang", W.J.S. Poerwadarminta menjelaskan bahwa ada dua hal penting dalam mengarang, yaitu berguru dan berlatih. Guru mengarang yang utama adalah membaca. Hal ini berarti sebelum kita berlatih mengarang novel, misalnya, perlu membaca novel yang telah ada (1984 : 11-12). Tentu saja, pendapat demikian baru sebagian kecil dari seluruh aktivitas proses kreatif.

Oleh karena ada tuntutan semacam itu, tidak menutup kemungkinan jika pengajaran proses kreatif penciptaan karya sastra di sekolah terbengkelai, jika enggan dikatakan terabaikan. Hal ini cukup beralasan, diantaranya karena pengajar sastra kurang dan bahkan tidak memiliki pengalaman kreativitas yang mapan. Padahal, suatu hal yang kurang memungkinkan jika harus mengambil seorang pengarang dari luar sekolah. Akibatnya, jika pengajaran proses kreatif cipta sastra itu terpaksa diberikan, tidak mustahil hanya asal-asalan saja.

Perlu disadari, sekolah adalah ladang penyemaian bibit pengarang, meskipun tidak sedikit pengarang kreatif lahir dari luar sekolah -namun, bukankah Emha Ainun Najib, Linus Suryadi, Suparta Brata juga pernah sekolah ?

Berdasarkan hal tersebut maka uraian selanjutnya akan dicoba paparkan wawasan proses kreatif penciptaan sastra, dengan harapan dapat dicobatularkan kepada siapa saja. Meskipun demikian, uraian ini bukan berarti usaha mengisi kekosongan, melainkan sekedar memberikan alternatif. 


\section{B. PROSES KREATIF PENCIPTAAN KARYA SASTRA}

\section{Orientasi Kreativitas}

Proses kreativitas menurut buku The Creative Process, editor Ghisilin (dalam Drama, 1984 : 13) dinyatakan bahwa The Creative process is the process of change ... in the organization of subjective life artinya proses kreatif adalah proses perubahan dalam organisasi kehidupan pribadi. Jadi, proses kreatif itu bersifat personal. Setiap pengarang memiliki daya juang kreatif yang tidak dimiliki oleh penulis lain. Akibatnya, masalah yang sama jika ditulis oleh pengarang yang berbeda, dalam waktu yang sama sekalipun, hasilnya akan berlainan. Dari bekal pribadi tersebut, kreativitas merupakan suatu tindakan yang muncul dari keadaan yang istimewa, sebagai tanggapan terhadap lingkungannya. tanggapan ini akan menolong inisiatif mengulur imajinasi, sehingga menghasilkan sesuatu yang baru.

Kayam (Endraswara, 1993 : 124) mengemukakan bahwa proses kreatif tidak sekedar to have and to have more (memiliki lebih banyak), tetapi to be and to be better (memiliki lebih baik). Usaha demikian juga beralasan, karena menurut Brata (1992 : 98) bahwa bagi pengarang kreatif pasti akan selalu berusaha meningkatkan kemampuannya.

\section{Tahap-tahap Proses Kreatif}

Rhodes (dalam Roekhan, 1989 : 32) menjelaskan bahwa proses kreatif penciptaan karya sastra melalui empat tahap : (1) persiapan, yatu tahap pemunculan ide, (2) inkubasi, adalah tahap pematangan dan pengolahan ide atau "pengiriman ide", (3) iluminasi, adalah tahap penuangan ide, dan (4) verifikasi, adalah tahap memacu kreativitas.

Tahap-tahap tersebut masih terlalu global. Maka Endraswara (1991 : 5 - 12) memerinci tahap-tahap kreativitas cipta sastra sebagai berikut :

\section{1) Tahap Penggalian}

Tahap ini meliputi langkah-langkah : (1) kepekaan, pengarang yang kreatif harus peka terhadap fenomena kehidupan. Langkah ini sebagai loncatan untuk menggali ide atau ilham, mudah tanggap sasmita terhaap 'spirit of age' (semangat zaman), misalnya. Dari langkah ini gagasan akan timbul yang berupa maksud, pikiran, cita-cita, dan harapan yang masih merupakan bahan mentah. (2) Sublim itas, yaitu keagungan dan keindahan. Langkah ini terjadi setelah pengarang menangkap gejala, lazimnya mereka lalu seperti keluar pada malam 
hari memandangi bintang-bintang di langit. Dimungkinkan, ia merasa kecil, merasa tak berarti, merasa serba kurang, atau bahkan merasa dirinya ada dan diadakan. Mungkin juga timbul pertanyaan tentang ada dan yang mungkin ada. (3) Abstraksi, adalah pemilihan dan pemilahan gagasan yang akan dituangkan. Dalam proses ini, ibarat orang memasak 'bakmi', pengarang mulai meramu gagasan dengan visi (panorama) dan segala hal yang telah lekat dalam dirinya. (4) Menelorkan embrio, yakni tidak berbeda dengan 'janin' manusia, embrio itu bakal karya. Embrio adalah hasil pengimajinasian yang siap pakai. Embrio juga merupakan 'core meaning' (inti karya). (5) Inkubasi, istilah ini meminjam batasan Brewater Smith (dalam Jatman, $1985: 116$ ) adalah pengerangan atau penetasan embrio. Jika ayam mengerami telurnya sampai 21 hari inkubasi pengarang bisa berjam-jam, berhari-hari, berbulan-bulan, bahkan bertahun-tahun.

\section{2) Tahap Penuangan}

Pada saat menuangkan embrio ke dalam karya, pengarang akan mencurahkan seluruh pikiran, perasaan, dan keinginannya. Pada saat ini, jika pengarang ingin berhasil, sadar atau tidak, akan melakukan berbagai hal : (1) Ersatz-stimuli, adalah pikiran pengarang terhadap konsumen karya yang akan dihasilkan. Ini merupakan 'the art of literature' (seni kepengarangan). Pengarang akan mencoba mengidentifikasi konsumen mulai dari tingkat sosial, umur, pendidikan, lokasi, dan lain-lain, (2) Wishful-thingking, adalah impian khayal pembaca ketika berhadapan dengan karya. Terkait dengan ini, maka pengarang juga memikirkan secara antisipasif keinginan pembaca, yang lazimnya berhubungan dengan persoalan universal manusia, (3) Rethorika, adalah teknika mengobor perhatian pembaca agar mereka terlibat dengan keinginan pengarang. Dengan rethorika, pengarang dapat menerapkan 'akrobatik' melalui improvisasi kata, logika, alur dan lain-lain. Atau pengarang berusaha menciptakan sesuatu yang gaib, aneh, dan luar biasa, (4) Pathos, yaitu perasaan simpati dengan apa yang terjadi dalam karya dan empati ialah merasa secara langsung terlibat di dalamnya, (5) Utopia, adalah penerapan impian khayal yang terkadang melanturlantur, sehingga karya itu lebih hidup, (6) Obsesi, yaitu lamunan yang seakanakan kesurupan, sehingga dapat menampilkan karya yang menggetarkan pembaca. Di sinilah penciptaan dunia yang mungkin ada bisa muncul. Bayanganbayangan yang aneh dapat lahir, (7) Chaos, yaitu ketika pengarang menelorkan obsesinya, kadang-kadang diwarnai oleh situasi kejiwaan yang 'kacau balau' selanjutnya ia seperti orang 'gila' bisa menciptakan sesuatu yang tidak terduga. 
Mungkin, melalui chaos, karya yang telah direncanakan, bisa berubah. Namun, erubahan yang serta-merta itu justru membuat karya lebih manis, (8) Katarsis (denoument), yaitu istilah dalam drama tragedi untuk menyucikan agar penonton 'muak' dan 'lega'. Dalam cerita pengarang berusaha menciptakan moral yang dapat dipetik oleh pembaca. Penampilan nafas profetik, religi, sufistik, dan filsafati adalah penting dalam hal ini, dan (9) Eksgeresi, ialah pengungkapan yang dilebih-lebihkan, ditonjol-tonjolkan dengan maksud untuk memikat pembaca. Di sini unsur stilistika besar peranannya.

\section{3) Tahap Koreksi}

Menurut Hakim dkk, (1983 : 62) setiap karangan membutuhkan revisi. Biasanya suatu karangan paling tidak memerlukan revisi dua kali. Seorang yang belajar mengarang adalah seumpama orang yang diceburkan ke laut berenang, kita belajar, sementara kita sedang mengarang.

Tahap ini dilakukan dengan pembacaan karya oleh pengarang sendiri. Di sini, pengarang bersikap sebagai pembaca pertama, bukan sebagai 'pengarang'. Oleh karena juga harus obyektif. Jika dibaca sendiri belum menarik, apalagi bagi orang lain.

Dengan koreksi ini, pengarang hendaknya tidak enggan merubah bahasa, memotong bagian-bagian yang mengganjal, 'menggunting' bagian-bagian yang kurang pas, dan 'melipat' di sana-sini. Koreksi dapat dilakukan berkali-kali, dapat diselingi membaca-baca karya orang lain, sehingga timbul greget untuk memperbaiki. Dalam kaitan ini, memang, bisa saja pengarang terpaksa membongkar karya yang telah jadi.

\section{4) Tahap Introspeksi}

Tahap introspeksi adalah keterbukaan pengarang untuk menerima kritik dari pembaca. Kritik secara estetis dan bukan menyacad atau bahkan 'membunuh' akan berpengaruh terhadap kematangan pengarang. Pengarang kreatif tidak akan anti kritik. Bukankah banyak pengarang menjadi terangkat juga atas kritik ? Oleh karena, pengarang perlu membaca diri seluas-luasnya, terlebih lagi jika karya itu akan dibukukan.

\section{Proses Kreatif Sebuah Pengalaman}

Apa yang akan dikemukakan ini bertumpu pada sebuah pengalaman yaitu pada saat menulis cerpen berjudul "Mripat" (Djaka Lodang, 7 Agustus 1992) 
dan Jongko (1994). Pengalaman ini sangat bersifat personal dan mungkin dapat disebut sebagai kasus penciptaan. Boleh dikatakan sebagai kasus karena telah disadari bahwa dalam penciptaan ratusan cerpen tidak seluruhnya melalui tahap proses kreatif yang telah diuraikan di muka. Ada sebagian cerpen yang karena alasan tertentu, kadang-kadang penciptaannya meloncat dari tahap proses kreatif. Sedangkan cerpen "Mripat" termasuk diantara karya yang melalui tahap proses kreatif.

Pada tahap penggalian yang akan disebutkan ini lebih berhubungan dengan proses batin. Oleh karena itu paparan ini mungkin lebih bersifat imajinatif. Tahap ini, bermula dari (1) kepekakan yakni mengapa semua orang menggunakan mata, di jalan-jalan orang melihat hal-hal erotik, di tempat hiburan orang sengaja mencuci mata dan lain-lain. (2) Sublimitas, yakni apakah kita dikaruniai mata sekedar untuk melepas kesenangan? ? Jika demikian bagaimana bagi orang buta. (3) Abstrak, mengapa kita dapat melihat dengan memejamkan mata bahkan lebih cermat seperti kamera film ? (4) Menelurkan embrio, mungkinkah kita mencukil mata kita sendiri yang menjadi sumber dosa ini ? (5) inkubasi, dari keempat tahap tadi, direnungkan beberapa waktu sehingga menetaskan ide bahwa kita kadang-kadang sadar bahwa mata perlu dicuci dari dosa.

Tahap penuangan, tahap ini meliputi berbagai kegiatan yakni (1) ersatz stimuli dalam hal ini antara lain penulis membuat stimulasi sebagai berikut "Awit seka jaman lan jantrani, jalaran seka ambale geni lan kukuse Den Penceng lega lila kelangan mripate". Mungkinkah tokoh ini tega menghabisi matanya sendiri ? (2) wishful - thinking, mencoba meraba-raba keinginan pembaca yakni Den Penceng akan membawa pisau dengan ucapan : "O, mripatku sayang, cekake wis nasib bego apa cilakamu mugha sing genah aku wus sunarah, pasrah yen mengko kowe malah basok dadi bathang yo nasibmu". (3) rethorika, yakni akrobatik lukisan antara lain: "Den Penceng ngobat-abitke pesani njur di wus kambi nyuwara ha - ha - ha. Cat - cat cat". (4) patos yakni pada saat Den Penceng siap mencukil mata ada tokoh tak dikenal yang mengingatkan niatnya (5) utppia yakni pada saat Den Penceng diingatkan terjadi perdebatan dimatanya ada klilip pada hal tidak (6) obsesi, Den Penceng menganggap bahwa matanya termasuk : mripat keneker, mata yuyu, mata walangan, mata iwaken, mata kranjang, dan seribu mata lain (7) Chaos, penulis berusaha melantur, ketika Den Penceng akan mencukil matanya, dihadirkan tokoh dokter yang biasa memegang alat operasi mata, agar memeriksa mata Den Penceng, (8) Katorsis, penulis berusaha memasukkan akar budaya 
Jawa, yaitu prinsip othak-athik mathuk, sehingga Den Penceng sampai di dapur (tempat kotor) dia lalu menemukan air dan alat-alat dapur yang mengandung simbol filosofis Jawa, dan (9) ebsogerosi, lukisan yang berlebihan tampak pada gagasan Den Penceng, jika telah lepas matanya, akan kaul dengan nanggap wayang lakon Murwokolo.

Pada tahap koreksi, penulis berusaha mengoreksi berbagai hal yang sulit dibeberkan. Bahkan ketika cerpen Mripat dikirim ke redaksi Djaka Lodang, hampir terjadi revisi karena redaksi keberatan model cerpen inkonversional ini. Namun, revisi itu terjadi hanya pada perdebataan dan penjelasan penulis.

Pada tahap introspeksi terjadi ketika cerpen itu dimuat, ternyata banyak surat dan tilpun yang masuk redaksi, hampir semua pembaca merasa bingung. Kenyataan ini menjadi bahan penting bagi penulis. Anehnya, selang beberapa bulan lagi, redaksi justru minta model karya serupa.

Demikian rentetan penciptaan cerpen "Mripat". Apa yang disajikan ini sekedar benang merah saja, bahkan apa yang terungkap dalam kutipan itu, hanya sebagian kecil saja, sebab jika harus disajikan seluruhnya jelas tidak adil. Mungkin hasilnya akan ke arah apresiasi kreatif terhadap karya sendiri, ini jelas tidak obyektif. Maka, lebih berharga bila para peminat membaca langsung cerpen tersebut dan mencoba berkarya.

\section{SIMPULAN}

Dari uraian di atas dapat disimpulkan bahwa proses kreatif penciptaan karya sastra memang unik dan khas. Kreativitas setiap pengarang memang berbeda satu dengan yang lain, kendatipun secara umum ada kesamaan-kesamaan tertentu. Secara umum, pengalaman kreatif itu akan mencapai 'puncak' memang berproses, tumbuh, dan trial and error. dan bukan segera puas dengan hasil yang sekali jadi.

Meskipun proses kreativitas itu bersifat personal, namun memiliki arah yang sama, yakni menciptakan yang to be and to be better dan pengarang selalu meningkatkan diri. Hal ini juga dipengaruhi oleh pengalaman jiwa kepengarangan masing-masing. Pengalaman jiwa inilah yang akan mewarnai corak kreativitas yang muncul.

Penciptaan karya kreatif memiliki tahap-tahap (1) persiapan atau penggalian, (2) penuangan, (3) koreksi, dan (4) mawas diri. Masing-masing tahap terdiri dari langkah-langkah yang perlu ditempuh oleh pengarang, jika 
ingin berhasil dalam penciptaan. Paa kenyataannya, tahap-tahap itu bisa diterapkan dalam 'pengajaran' proses kreatif dan juga dapat ditularkan oleh pengarang satu dengan yang lain.

\section{DAFTAR PUSTAKA}

Atmowiloto, Arswendo. 1995 Mengarang Itu Gampang. Jakarta : Subendra Citra Pustaka.

Darma, Budi. 1984. Sejumlah Esai Sastra. Jakarta : PT Karya Unipress.

Endraswara, Suwardi. 1991. Menapak Kreativitas Cerbung Kumalaretna. Yogyakarta : Makalah Diskusi Sastra SSJY.

Hakim. AA, dkk. 1971. Teknik Mengarang. Yogyakarta : Yayasan Kanisius.

Jatman, Darmanto. 1985. Sastra, Psikologi dan Masyarakat. Bandung : Alumi.

Lubis, Mochtar. 1981. Teknik Mengarang. Jakarta : Kurnia Esa.

Nasution, Nancy. 1984. Anda Mau Jadi Pengarang ? Jakarta : PT BPK Gunung Mulia.

Poerwadarminta, WJS. 1984. ABC Karang Mengarang. Yogyakarta : UP Indonesia.

Tarigan, Henry Guntur. 1986. Menulis Sebagai Suatu Keterampilan Berbahasa. Bandung : Angkasa.

Widyamertaya, A. 1978. Kreatif Mengarang. Yogyakarta : Yayasan Kanisius.

Wisjnu, Hingga Rd. 1963. Teknik Mengarang Cerita Pendek, Sandiwara Radio, Skenario Film. Jakarta : Haruwa Hidup. 